\title{
Water Footprint Assessment and Water-Energy-Food Nexus for Domestic and Institutional Sectors in Klang Valley, Malaysia: a Review
}

\author{
Nurul Azmah Safie ${ }^{\text {* }}$, M.A.Malek ${ }^{2}$, Z. Z. Noor ${ }^{3}$ \\ ${ }^{I}$ Department of Civil Engineering, Universiti Tenaga Nasional, Malaysia. \\ ${ }^{2}$ Institute of Energy Policy Research (IEPRe), Universiti Tenaga Nasional, Malaysia. \\ ${ }^{3}$ Centre for Environmental Sustainability and Water Security. Universiti Teknologi Malaysia \\ *Corresponding Author: azmah938@gmail.com
}

\begin{abstract}
Change in climate, increasing world population and industrialization have placed considerable stress on water availability at certain places. Water Footprint accounting is a reliable technique that can be used for a better water management. This study focuses on establishing a doable methodology on water footprint accounting and assessment for direct water consumption from domestic and institutional sectors located in an urbanized environment such as Klang Valley, Kuala Lumpur. It includes investigation of Water Footprint at domestic household, schools, colleges, terminals and offices in Klang Valley. The value of water consumption, water production and water pollution will be determined using Hoekstra's approach for green water, blue water and grey water. In addition, findings from this study will be linked to two other elements namely energy and food. This link is named as Water-Energy-Food Nexus. This study will establish the quantity and criteria of Water-Energy-Food Nexus specifically tailored to domestic and institutional sectors in Klang Valley.
\end{abstract}

Keywords: Water Footprint; Water-Energy-Food Nexus; water management; Klang Valley

\section{Introduction}

\subsection{Water Footprint Concept}

Water Footprint (WF) concept was introduced in year 2002 at the International Expert Meeting on Virtual Water Trade,that was held in Delft, the Netherlands (Hoekstra, 2003). According to Maite M. Aldaya (2010), water footprint is an numerical indicator use for a consumer or producer (the data can be individual or a group data). Water use is measured in terms of water volume consumed and water polluted per unit of time. It is sensitive to geography as denser population area tends to have higher water footprint. A water footprint can be calculated for process, product, consumer, group of consumers such as municipality, province or state and producer such as public organization and private enterprise.

WF can be clasify into three kinds which are green, blue and gray water. The green water is the soil water held in the unsaturated zone, produced by rainfall and available to plants only. Blue water refers to liquid water such as in rivers, lakes, wetlands and aquifers or also known and as groundwater. Irrigated agriculture receives blue water (from irrigation) as well as green water (from precipitation), while rain agriculture receives only green water. The green WF is thus the rainwater consumed by crops. The grey WF is the volume of water needed to dilute a certain amount of pollution.

\subsection{Water-Energy-Food Nexus Concept}

In 20150, the world population is estimated to be more than 9 billion people thus it is a challage to meets the human demand on water, food and energy. The lingkage of food, energy, and water is one of the most complex issues that face society. There is no more land to exploit, and the supply of fresh water in some areas of the world limits the use of land for food. All solutions must also deal with the overlay of global climate change. Meeting current and future populations needs will require security in food, energy, and water continuously. The main reason of this nexus is to promote a green technology which use the concept of optimization the current resources for the future generations. For this study, a ratio of water usage, food intake and energy consumed will be analyzed to find the pattern of this nexus.

\section{Research Question and Research Problem}

The focus on freshwater is important because of its growing scarcity. The average global WF between year 1996 and 2005 was over 9,000 billion $\mathrm{m} 3$ per year. The agricultural production $92 \%$ of this total, followed by blue (74\%) and gray water (11\%). In addition, due to excessive densification of urbanized area, there is progressive increase of water footprint in practically all sectors in municipalities, institutions, terminals and offices.

Similar to carbon footprint (CF), WF is tedious to be calculated. Even though the concept started in year 2002, there are still less research work conducted pertaining to this issue. More studies 
should be carried out in order to establish procedure on how to determine the quantity of water footprint, especially in municipal sector. Awareness on WF must be further enhanced among the community. The main concern of this study is how much the types of housing area (comparison between high, medium and low cost housing area) influenced the WF and how this WF can be traced and calculated. Then based on the data, the pattern of water consumption can be analyzed.

Apart from that, it is essential to study the intake of food in certain household. Their lifestyle plays an important role as vegetarian tend to not take the meat. The meat itself needs a lot of water to produce.

\section{Literature Review}

\subsection{Influencing Factors of Water Footprint}

The amount of water used in any activity are strongly determined by the supply of water available to fullfill the demand for that certain activity. Both the supply and demand of water are determined by variable and behavior or lifestyle of people living in those places.

a) Population

At the most critical level, water is needed to supply the basic domestic needs, in quantities directly proportional to the number of people which means that more people needs more supply unless he or she are practicing a water, energy and food saving. Besides, people living in bigger household tend to have different consumption of water use, and tend to use different amount of water as compared to people in low and medium cost household This pattern is similar for food intake and energy consumed such as electric, solar and coal.

b) Technology used

Changes in technology may affect the availablity, supply and demand level of water use. Similarly, urban housing uses more water demand that in rural area. However, technology development can also permit to economize water. Indoor water efficiency equipment such as plumbing fixtures and computerized irrigation management technique, frequently result in reduction of water use. On the other hand, failure to employ modern technology may means lower in quantity of water and higher costs of available supply. This pattern is also similar for food intake and energy consumed

c) Economics

Economics condition may affect water supply and demand. Water prices thru water tariff in certain country may be boost as there will be more additional cost needed to pumped and treated the water before it can be used by the consumers. Automatically, the user has to pay more for the water and energy tariff. Then the cost of living will be increased along with the changes. The economics conditions also generally influence the amount of food intake and energy consumed.

d) Lifestyle

Lifestyle of certain people in a household, institution will influence the amount of blue, green and grey water. It depends on the way they consumed the water such as how long is the time to take bath per person, how many times they take their bath, did they let the water to flow during washing the plates, how often did they wash their cloths per week and etc. This lifestyle will determine the WF in a certain household. From there, it cannot be concluded that more people in a household will consume more water as it also depends on the lifestyle.

\subsection{Water-Energy-Food Security}

The concept of the water-energy-food nexus was launched in Bonn 2011 Nexus Conference, theme as "The Water Energy and Food Security Nexus-Solutions for the Green Economy" to contribute to the United Nations Conference on Sustainable Development (Rio 2011). The conferences theme is to counterback the changes that may happen due to changes in climate, urbanization and population growth. These are causing increased demand on water, energy and food resources, pushing communities with an increasing number of trade offs and possible conflicts among these three resources which have complex connections. For example, US NIC (United States National Intelligence Council), 2012) states that the demands for water, energy and food are estimated to increase by $40 \%, 50 \%$ and $35 \%$ respectively by 2030 . Nowadays, there are many WEF nexus conferences but yet the policy has not been implemented in many countries.

\subsubsection{Food Security}

The components of food security are:

(1) food availability

(2) access to food

(3) utilization

(4) food stability over time ( Ericksen, 2008; Schumidhuber and Tubiello, 2007).

Food insecurity is a complex phenomenon which varies through different stages as the condition becomes more severe from time to time. Each stage consists of certain conditions and experiences face by people of food insufficiency to fully their basic needs. Household food security can be divided by three categories such as;

I. Food security is define as food that be can be access by all the people, for all the time. The food in enough, safe and nutritious.

II. Food insecurity is define as limited access of food, at certain time. The food may be enough but not nutritious or the food may be not enough and have certain nutrition value.

III. Hunger is the feel of pains that face one individu caused by the unadequate amount of food. This may lead to malnutrition

\subsubsection{Water Security}

The components of water security are:

i. water access

ii. water safety

iii. water affordability to allow each person to lead a clean, healthy and productive life, while protecting the natural environment (Global Water Partnership, 2000).

\subsubsection{Energy Security}

The components of energy security are:

I. continuity of energy supplies relative to demand

II. physical availability of supplies

III. sufficient supply to satisfy demand at a given price (Department of Energy Climate Change [DECC], 2009; International Energy Agency [IEA], 2001).

\subsection{Water-Energy-Food Nexus Framework}

One of the main reason the WEF nexus framework is being done is to manage and govern the lands. The main considerations are based on social, environmental and economic objectives. The implementations are done to ensure the water, energy and food security in the future. It demonstrates the interconnections between these three main resources. The overview of this frameworks allow us to have a better knowledge of:

I. the nature and the relationship between these three sources

II. the consequences if one of the sources are changing

III. improve policy development on these three sources

One of the relevant example of WEF Nexus conferences are Bonn2011 nexus Conference on the Water, Energy and Food Security Nexus: Solutions for the green economy (Hoff, 2011). 
The main purpose of this conference is to study the connection between these three resources under influences of trade, investment and climate changes. The conference has successfully developed a framework as follow.

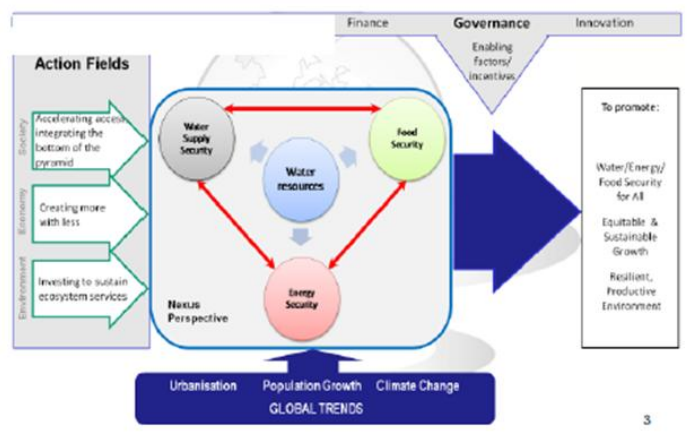

Figure 1: Framework on Bonn2011

\section{Scope}

The scope of this study must be around Klang Valley. They can be divide into three zones. They are middle, south and north of Klang Valley.

Table 1: Classification of Zones in Klang Valley

\begin{tabular}{|l|l|}
\hline Zones, Klang Valley & Example of Area Covered \\
\hline \multirow{3}{*}{ North } & $\begin{array}{l}\text { Wangsa Maju, Keramat, Batu Caves, } \\
\text { Kepong }\end{array}$ \\
\hline \multirow{3}{*}{ Middle } & TTDI, Damansara, Jalan Raja \\
Chulan, Kg Baru
\end{tabular}

And then, the household can further classify based on their types of household. The institutions, offices and terminals can be classify clearly too.

Table 2: Classification of Sectors

\begin{tabular}{|l|rl|}
\hline Sectors & Classification \\
\hline Domestic (Household) & 1) & village \\
& 2 ) & apartment \\
& 3 ) & condominium \\
& 4 ) & terrace \\
& 5 ) & semi detached \\
\hline Institutions & 1) & kindergarten \\
& 2) & primary school \\
& 3 3) & secondary school \\
& $4)$ & college \\
& $5)$ & university \\
\hline Terminals & 1) & KTM station \\
& 2) & KL Central \\
\hline Offices & 1) & Single storey \\
& 2) & Double storey \\
& 3) & Shared building \\
& $4)$ & One whole building \\
\hline
\end{tabular}

\section{Method/ Techniques}

By using Hoekstra 2011, the WF of a consumer or group of members can be calculated by adding the direct WF of the individual.

Wfcons $=$ Wfcons, dir + Wfcons,indir[volume/time $]$

\section{Expected Results}

The expected result can be obtained based on the objectives stated. 1) First objective is to list all the variables that may affect the water usage, food intake, energy consumed of consumer in domestic and institutions sector of Klang Valley. Then the expected results are that the variables play a major parts in water, energy and food consumption. Some of the variables are gender, age, occupancy, types of household, level of institutions, number of people and etc.

2) The second objective is to analyze the pattern of water, energy and food consumption of consumer in domestic and institutions around Klang Valley through a survey. The expected results is that the pattern may vary depends on economy of certain household. Rich people tend to have water saving appliances and they do not really care about the food prices and water tariff.

3) The third objective is to conclude the relationship between WF of domestic and institutions with the WEF nexus. As water is the most important resources in order to maintain a life, the water have a strong connection with energy and food. Thus, the value of WF (water consumption, water pollution and water production) can be compared and link with WEF thru a WEF framework.

\section{Significant of Study}

Water is the most important substances on earth. All plants and animals must have water to survive. Apart from drinking it to survive, people have many other uses for water. Freshwater is a scarce resource; its annual availability is limited and demand is continuously growing. The WF of humanity has exceeded sustainable levels in several places and is unequally distributed among people. Therefore, the WF is an indicator to calculate the water usage consumed by consumer directly and indirectly. WF assessment refers to the full range of activities to quantify and locate the WF of a consumer, to assess the environmental, social and economic sustainability of WF and to formulate a response strategy. It can be concluded that this research may contributed to the nation by;

i. analyse how human activities or specific products relate to the issue of water, energy and food scarcity and how human activities can become more sustainable from a environmental perspective

ii. encourage more user friendly tools such as water saving technology used in household appliances

iii. implementation and revision of water tariff, staple food subsidized by the government in a nation as an response strategy

\section{Discussion}

Water resources engineering is a field that continuously growing and changing from times to times. This is because, the lifestyle, economy, trends and urbanization keeps happen every single day. The study of water pattern is important to helps hydrologist and policy makers to managed the water properly. Not to be forgotten is the food and energy. As water is connected with food (known as water-food nexus) and energy (known as water-energy nexus), thus the interconnection becomes more complex. Further detail study must be carry out in order to analyzed the current pattern of there three resources.

Producing sustainable urban environments, therefore, requires a political and administrative system that involves all relevant social play at all geographical scales. In addition, it requires a policy framework that does not isolate the circulation of water, food and energy from other sustainability-related processes. In fact, it requires a more comprehensive and integrated approach in which supply of water is integrated with health and sanitation policy, ecological considerations, socio-economic processes and governance systems. The increasing fragmentation of policy domains (partly as a result of commodification and privatisation) makes this objective more remote than ever. 


\section{Acknowledgement}

This study is supported by Universiti Tenaga Nasional- BOLD Scholarship 2017/2018.

\section{References}

[1] Alessandro Manzardoa, Andrea Lossa, Wieslaw Fialkiewiczb, Wolfgang Rauchc,Antonio Scipionia, "Methodological proposal to assess the water footprint accounting ofdirect water use at an urban level: A case study of the Municipalityof Vicenza", Ecological Indicators, Vol 65, p165-175, (2016)

[2] Bradley G. Ridoutt \& Stephan Pfister, "A new water footprint calculation method integrating consumptive and degradative water use into a single stand-alone weighted indicator ",The International Journal of Life Cycle Assessment, DOI 10.1007/s11367-012-0458$\mathrm{z},(2012)$

[3] D. Vanham and G. Bidoglio, "The water footprint of Milan", Water Science \& Technology, Vol 69.4, (2014)

[4] E. Swyngedouw, M. Kaïka and E. Castro, "Urban Water: A political-ecology perspective", Special Issue on Water Management in Urban Areas, Vol. 28, \#2, pp. 124-137, (2002)

[5] Gary Bickel, Mark Nord, Cristofer Price, William Hamilton, John Cook, "Guide to Measuring Household Food Security", available online: http://www.fns.usda.gov/oane, (2000)

[6] Kuishuang Feng a,b, Yim Ling Siu c,b, Dabo Guan b, Klaus Hubacek a, "Assessing regional virtual water flows and water footprints in the Yellow River Basin, China: A consumption based approach", Applied Geography, Vol 32, p. 691e701, (2011)

[7] Livia Bizikova, Dimple Roy, Darren Swanson, Henry David Venema, Matthew McCandless, "The Water-Energy-Food Security Nexus: Towards a practical planning and decision-support framework for landscape investment and risk management", International Institute for Sustainable Development, (2013)

[8] M. M. Mekonnen and A. Y. Hoekstra, "The green, blue and grey water footprint of crops and derived crop products", Hydrol. Earth Syst. Sci., 15, 1577-1600, (2011)

[9] Tom Gleeson1, YoshihideWada2, Marc F. P. Bierkens2,3 \& Ludovicus P. H. van Beek2, "Water balance of global aquifers revealed by groundwater footprint" doi:10.1038/nature11295, Vol 488, (2012) 